\title{
Breakage of a Biliary Plastic Stent - A Potential Risk of Sideholes
}

Biliary stent exchange is usually considered a safe procedure where problems related to manipulation of an occluded stent are seldom experienced. A case of plastic stent breakage, probably related to the stent's design, is reported.

A 87-year-old male with cancer of the prostate and cardiac decompensation was admitted with jaundice. Ultrasonography showed cholestasis, and a $2 \mathrm{~cm}$ stone in the common bile duct near the papilla was suspected. Endoscopic retrograde cholangiopancreatography (ERCP) showed a $1.5 \mathrm{~cm}$ stricture $2.5 \mathrm{~cm}$ above the papilla. After dilatation with a tapered $10 \mathrm{~F}$ dilator, a $10 \mathrm{~F} 6 \mathrm{~cm}$ straight biliary Teflon stent with short flaps and sideholes at the flapcuts was inserted. Endobiliary brush biopsy showed no malignant cells. The jaundice resolved, but 10 weeks later the patient was readmitted with septic cholan- gitis. The occluded stent was exchanged for a similar stent over a guidewire correctly located within the intrahepatic ducts. The jaundice persisted, and an attempt at inserting a second stent was not successful because the stricture was very tight. Instead, the stent was retracted $1 \mathrm{~cm}$ to ensure that its tip was located freely within the bile duct. A flow of clear bile was observed. After a temporary decrease the bilirubin level increased again after one week, and his general condition deteriorated. A stent exchange was therefore planned, but during extraction with a snare around the duodenal end the stent disintegrated at the level of the three proximal flaps (Figure 1), and the proximal end including the flaps, was stuck in the tight stenosis (Figure 2). Balloon extraction was not successful, but another plastic stent was positioned alongside and drained colourless bile. Afterwards the cardiac de-

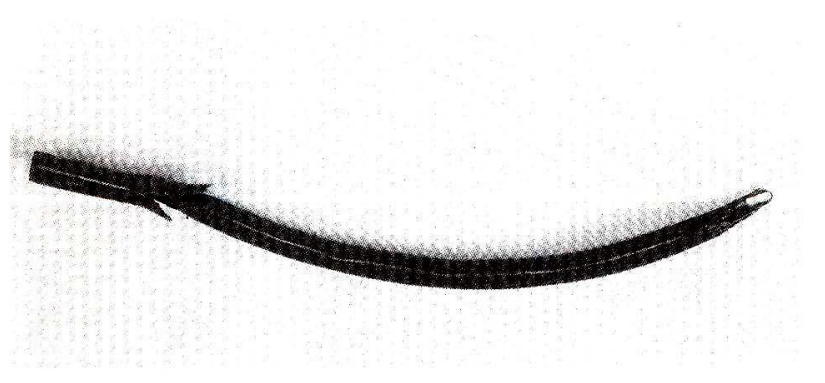

Figure 1: Broken plastic stent; the concave cuts at the point of disintegration are seen. The design of the flaps are seen in the intact distal end.
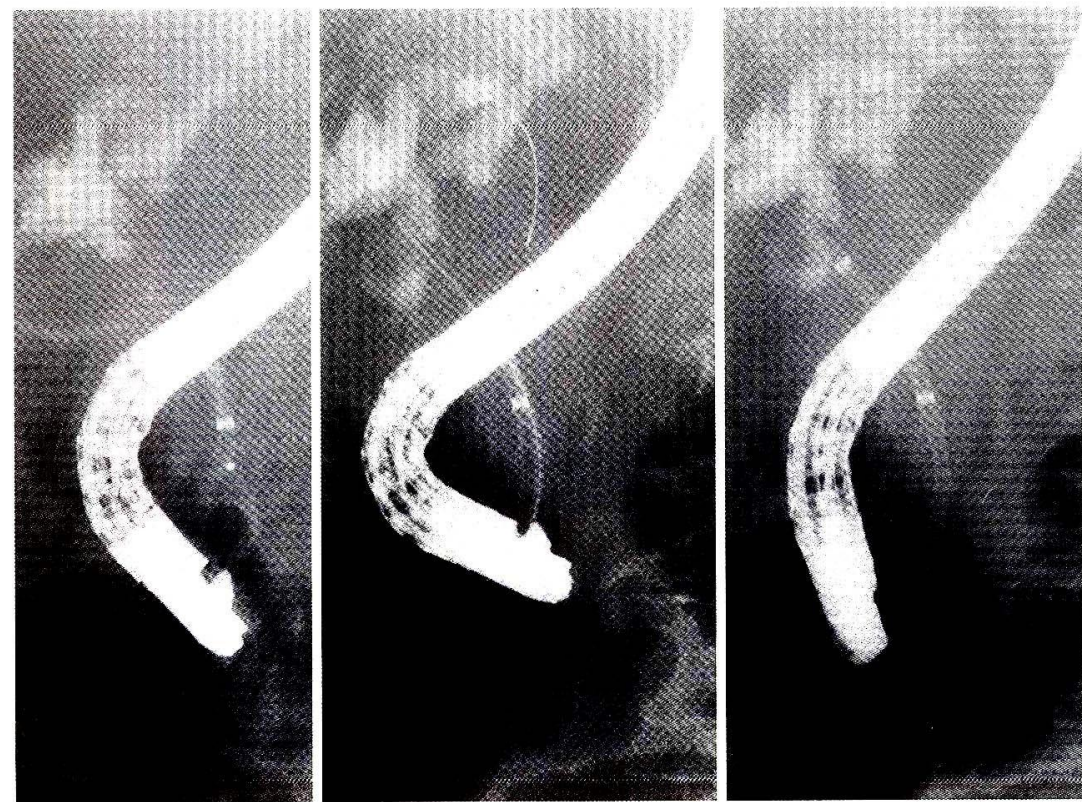

Figure 2: From left to right: the retained proximal fragment stuck in the stricture; passed with a wire and subsequently passed with a second stent. 
compensation worsened, and the patient died two days later. No autopsy was done, as the relatives did not give consent.

No similar complication involving plastic stents has been reported, but mechanical breakage of a metal stent has recently been described (1). The design of the present stent, with three closely placed cuts where the short flaps were located, probably caused weakness leading to breakage. Acute angulation during extraction, combined with the flaps being stuck in the tight stricture, is a possible contributing factor. It could be speculated whether the use of a wireguided extraction device (2) would have resulted in uneventful extraction. In this case the "snare beside a wire" technique (3) would probably not have avoided the mishap. The design of the stent in question should be modified to increase the distance between the cuts to strengthen it. Similarly, stents with long flaps, but without sideholes or cuts going completely through the material (4) could be assumed to have weak areas if the cuts are too deep. This should be taken into consideration in the continuing development of single-layer plastic stents.

S. Adamsen, M. Jendresen

Dept. of Surgery A, Section for

Gastrointestinal Surgery and Endoscopy,

Hillerød Hospital, Hillerød, Denmark

\section{References}

1. Born P, Rösch T, Classen M. Breakage of an endobiliary metal stent. Endoscopy 1996; $28: 526$

2. Soehendra N, Maydeo A, Eckmann B, Bruckner M, Nam VC, Grimm H. A new technique for replacing an obstructed biliary endoprosthesis. Endoscopy $1990 ; 22: 271-2$.

3. Tarnasky P, Morris J, Hawes RH, Hoffmann BJ, Cotton PB, Cunningham JT. Snare beside-a-wire biliary stent exchange: a method that maintains access across biliary strictures. Gastrointest Endosc 1996; 44: 185-7.

4. Binmoeller KF, Seitz U, Seifert H, Thonke F, Sikka S, Soehendra N. The Tannenbaum stent: a new plastic biliary stent without side holes. Am J Gastroenterol 1995; 90: 1764-8.

Corresponding Author

S. Adamsen, M.D.

Dept. of Surgery A

Section for Gastrointestinal Surgery

and Endoscopy, Hillerød Hospital

3400 Hillerød, Denmark

Fax: + 45-48293565

E-mail: sven.adamsen@dadlnet.dk 